\title{
ANÁLISE DO PROCESSO DE GESTÃO DA INFORMAÇÃO NOS PROJETOS ARTÍSTICO- CULTURAIS DESENVOLVIDOS PELO CENTRO CULTURAL PIOLLIN
}

\section{ANÁLISIS DEL PROCESO DE GESTIÓN DE LA INFORMACIÓN EN LOS PROYECTOS ARTÍSTICOS Y CULTURALES DESARROLLADOS POR EL CENTRO CULTURAL PIOLLIN}

\author{
Bruno de Araújo Ribeiro* \\ Júlio Afonso Sá de Pinho Neto**
}

\begin{abstract}
RESUMO:
Introdução: A Ciência da Informação é o campo teórico que estuda a ação mediadora entre informação e conhecimento, trabalhando a informação enquanto objeto que tem a potencialidade de gerar conhecimento no indivíduo e para a sua realidade. Neste sentido, a informação pode se estender ao conjunto de elementos que compõem um processo de gestão, de modo a ordenar, coordenar e distribuir correta, política e socialmente a informação, realidade que se estende também ao contexto das Organizações do Terceiro Setor.

Objetivo: Este trabalho teve como objetivo analisar as ações que compõem o processo de Gestão da Informação adotadas na implementação das oficinas artísticas desenvolvidas pela Organização Não Governamental Centro Cultural Piollin.

Metodologia: Esta investigação foi orientada sob uma abordagem quantiqualitativa, caracterizada como uma pesquisa exploratória, aplicada e descritiva, além do uso da pesquisa bibliográfica, documental e de campo para a coleta dos dados. Como instrumentos de coleta de dados foram utilizadas entrevistas semiestruturadas para todas as categorias de público, analisadas por meio da análise de conteúdo de Bardin (1979).

Resultados: Os resultados revelam que a ausência de uma gestão que contemple a informação como um elemento estratégico e transformador provoca carências e lacunas que podem influenciar no resultado almejado pelas oficinas, contribuindo para

*Mestre em Ciência da Informação pelo Programa de Pós-Graduação em Ciência da Informação da Universidade Federal da Paraíba (UFPB). E-mail: brunoribeirorp@gmail.com **Professor Doutor do Programa de Pós-Graduação em Ciência da Informação da Universidade Federal da Paraíba (UFPB). E-mail: sadepinho@uol.com.br
\end{abstract}


Bruno de Araújo Ribeiro, Júlio Afonso Sá de Pinho Neto

Análise do processo de gestão da informação nos projetos artístico-culturais desenvolvidos pelo Centro Cultural Piollin

reduzir os benefícios que poderiam trazer aos educandos, sendo que o maior deles é o de fazer uso de expressões artísticas como forma de educar para a cidadania.

Conclusão: Torna-se extremamente necessário ao Piollin envidar esforços no sentido de elevar a gestão da informação a um patamar estratégico, capaz de combater as carências e lacunas existentes em matéria de informação, auxiliando na consecução dos objetivos tão almejados pelas oficinas e pelo Centro.

Palavras-chave: Ciência da Informação. Gestão da Informação. Organizações Não Governamentais.

\section{INTRODUÇÃO}

No contexto da sociedade contemporânea, a informação revela cada vez mais a sua importância para diversos setores fundamentais da sociedade, suscitando um pensamento teórico e prático referente a questões sobre sua natureza, seus conceitos e potenciais benefícios direcionados ao indivíduo e à sociedade. Nesse sentido, a informação pode ser compreendida como um fenômeno social coletivo, que dá suporte à interação do sujeito usuário da informação e ao ambiente social e organizacional no qual ele está inserido (BARRETO, 1994).

De acordo com Barreto (1994), a informação, quando adequadamente assimilada, adquire a qualidade de um instrumento capaz de modificar o pensamento do indivíduo e de seu meio social, ou seja, a informação está destinada a amparar a produção, coleta, organização, assimilação, armazenamento, recuperação, distribuição, transformação e utilização de conhecimentos para um indivíduo ou grupo de pessoas de determinada realidade.

Nesse sentido, a informação pode ser compreendida como um fenômeno social coletivo, que dá suporte à interação do sujeito usuário da informação e ao ambiente social e organizacional no qual ele está inserido. Sob este aspecto, a Ciência da Informação pode ser vista como o campo teórico da reflexão da informação, ou seja, a ciência que estuda a ação mediadora entre informação e conhecimento. Trabalha a informação enquanto objeto que tem a potencialidade de gerar conhecimento no indivíduo e para a sua realidade, permitindo que a informação se estenda ao conjunto de elementos que 
Bruno de Araújo Ribeiro, Júlio Afonso Sá de Pinho Neto

Análise do processo de gestão da informação nos projetos artístico-culturais desenvolvidos pelo Centro Cultural Piollin

compõem o processo de um modelo de gestão que vai ordenar, coordenar e distribuir correta, política e socialmente a informação.

Dessa forma, e levando em consideração tais apontamentos, a Gestão da Informação assume uma importância estratégica também no contexto de Organizações do Terceiro Setor (OTS), pois possui a competência de estabelecer, por meio do uso estratégico da informação, ambientes dinâmicos que estimulem o envolvimento e o empenho dos integrantes da organização no desenvolvimento de ações propositivas e transformadoras. Levando em consideração tais aspectos, é imprescindível e necessário que as OTS não abram mão do uso de certos mecanismos de gestão, pois negligenciar tais elementos mais pragmáticos que avalizam a efetividade das políticas ali empreendidas comprometeria não só os seus propósitos, mas também a própria existência destas entidades, tendo em vista que a ausência de instrumentos e de uma cultura mais profícua de gestão produz, no contexto dessas organizações, certa passividade e aceitação de níveis moderados de eficiência.

Desse modo, fornecer a estas entidades uma visão para o uso estratégico da informação trará significativa contribuição, não só em relação às suas práticas de gestão, mas também no que diz respeito à sua capacidade de agir proativamente em relação aos projetos e ações sociais desenvolvidos em seu seio. À vista disso, a gestão da informação poderá proporcionar um ambiente de permanente diálogo e interação com os diferentes atores sociais, na expressão de suas demandas, de seus valores e propósitos sociais, bem como no cumprimento de sua missão perante a sociedade.

Nesse sentido, o presente trabalho tem por finalidade analisar 0 processo de Gestão da Informação em uma OTS, adotando como objeto de análise as oficinas artísticas desenvolvidas e oferecidas pela Organização Não Governamental (ONG) Centro Cultural Piollin, tendo como suporte, as bases conceituais e teóricas da Ciência da Informação. Destarte, este trabalho procura responder à seguinte problemática: de que forma e em que medida o processo de Gestão da Informação pode contribuir e auxiliar na consecução das atividades realizadas nas oficinas oferecidas pelo Centro Cultural Piollin? 
Bruno de Araújo Ribeiro, Júlio Afonso Sá de Pinho Neto

Análise do processo de gestão da informação nos projetos artístico-culturais desenvolvidos pelo Centro Cultural Piollin

O Centro Cultural Piollin está localizado no bairro do Róger, na cidade de João Pessoa - PB, e tem como missão, estimular o potencial expressivo e comunicativo de crianças, adolescentes e jovens, prioritariamente de setores populares, visando seu desenvolvimento pessoal e sua integração social através de uma proposta pedagógica que procura promover a educação por meio de uma linguagem artística. Possui a intenção de proporcionar uma experiência ocupacional e pedagógica para crianças e adolescentes em faixa de grande vulnerabilidade social, suscetíveis à violência e às demais mazelas que estão presentes em nossa sociedade. Segundo a instituição, seus projetos e ações funcionam como um elo de transformação cultural e social, que objetivam o incremento da difusão de atividades artísticas e culturais, em especial as de caráter pedagógico, voltadas para o público infanto-juvenil.

Dessa forma, este trabalho justifica-se, fundamentalmente, por incorporar a gestão da informação como um elemento efetivo, capaz de

promover modificações estruturais, comportamentais e informacionais à realidade do objeto de estudo em questão, na medida em que possui o potencial estratégico de corroborar para o desenvolvimento coletivo das várias competências direcionadas aos indivíduos e à sociedade.

\section{FUNDAMENTAÇÃO TEÓRICA}

Sob os aspectos históricos, evolutivos e revolucionários da humanidade, a informação sempre ocupou um papel fundamental como elemento organizador e ordenador do desenvolvimento do homem e de sua história. $\mathrm{Na}$ contemporaneidade, a importância da informação assume graus de elevação cada vez mais estratégicos, no sentido de estimular o pensamento científico às questões sobre sua natureza, seus conceitos e aos potenciais benefícios direcionados ao indivíduo e ao relacionamento com o mundo que o circunda. Nesse sentido, a informação, quando corretamente apropriada, assume a qualidade de um instrumento modificador da consciência individual, coletiva e, de um modo mais abrangente, de toda a sociedade (BARRETO, 1994).

Sem dúvida, a informação compõe a parte significativa e singular do conjunto de elementos básicos para a inteligibilidade dos processos, sejam 
Bruno de Araújo Ribeiro, Júlio Afonso Sá de Pinho Neto

Análise do processo de gestão da informação nos projetos artístico-culturais desenvolvidos pelo Centro Cultural Piollin

eles naturais ou culturais. Como processos entende-se "qualquer atividade ou conjunto de atividades que transforma recursos em produtos (entradas em saídas), e possui mecanismos de controle e verificação de qualidade" (MIRANDA, 2010, p. 98). Ou seja, o recurso, a informação, sob a gerência de um processo, torna-se produto, o conhecimento.

Num esforço para compreender este elemento balizador, Kobashi e Tálamo (2003, p. 9) fazem uso de um argumento metafórico, no qual a informação, assim como o alimento, é vista como um bem. "O bem, independente de sua natureza material ou simbólica, define-se como um objeto - material ou imaterial - que responde pela satisfação das necessidades físicas e culturais do homem". O bem, ou o conjunto destes, integra parte de um sistema estruturado que é composto pelos seguintes elementos: produção, armazenamento, distribuição, troca e uso. Desse modo, qualquer bem necessário que, por alguma razão, não esteja presente na estrutura desse sistema terá a propensão de gerar privações e desigualdades no âmbito da sociedade. Assim como a ausência de alimento provoca a fome, a ausência de informação provoca a privação do conhecimento (KOBASHI; TÁLAMO, 2003).

Em sentido oposto ao bem material, a informação apresenta-se como um bem simbólico, pois emerge, organiza-se e circula no interior da linguagem. Diferente ainda do bem material, que possui características finitas, o uso da informação não se esgota. Nesse sentido, a informação, assim como define Barreto (1994, p. 1), atua como mediadora na produção do conhecimento e é entendida, "em forma e substância, como estruturas significantes com a competência de gerar conhecimento para o indivíduo e seu grupo".

Nesse contexto, a Ciência da Informação passa a ser vista como uma instituição de reflexão da informação, ou seja, como o campo científico que estuda a ação mediadora entre informação e conhecimento em relação ao indivíduo, aos seus coletivos e à sociedade. Tal concepção também encontra concordância na afirmação de Kobashi e Tálamo (2003, p. 14), quando enfatizam que, na contemporaneidade, "o comportamento racional demanda conhecimento e o papel da Ciência da Informação é exatamente auxiliar 
Bruno de Araújo Ribeiro, Júlio Afonso Sá de Pinho Neto

Análise do processo de gestão da informação nos projetos artístico-culturais desenvolvidos pelo Centro Cultural Piollin

pessoas, os atores, que se encontram em situação problemática em relação ao uso do conhecimento".

A questão que se segue a estas proposições é justamente a forma de como se deve trabalhar a informação enquanto estruturas significantes, no sentido de direcioná-la ao seu desígnio principal, isto é, a de produtora de conhecimento para a sociedade. Desse modo, a problemática da informação se estende ao conjunto de elementos que compõem o processo que vai ordenar, coordenar e distribuir de maneira correta, política e socialmente a informação, ou seja, a Gestão da Informação. Barbosa (2008, p. 6), relaciona a origem moderna da gestão da informação aos trabalhos realizados por Paul Otlet (1934), em especial, à publicação do livro Traité de documentation, "marco fundamental do desenvolvimento da gestão da informação, disciplina que, na época, era conhecida como documentação".

A Gestão da Informação atua por meio da operacionalização de métodos e técnicas bem definidos, que cumprem uma função estratégica ao conduzir a informação a um processo de transformação planejado e orientado por uma racionalidade pragmática que Ihe é específica. Como bem define Miranda (2010, p. 99), "fazer gestão da informação significa dirigir e dar suporte efetivo e eficiente ao ciclo informacional de uma organização". Este ciclo representa as ações relacionadas à reunião ou captação, organização, codificação, criação, uso e distribuição da informação.

Nesse sentido, a gestão da informação deve ser concebida na organização sob um ponto de vista holístico, de modo que seus processos possam contemplar integralmente a gestão dos recursos informacionais, o uso das tecnologias de informação, as estratégias, políticas e os comportamentos relacionados à informação, com o objetivo de subsidiar e orientar os sujeitos organizacionais no desempenho de suas funções.

Portanto, levando em consideração todos os aspectos abordados até aqui, evidencia-se a informação como elemento imprescindível, dotado de uma estrutura significante capaz de modificar a consciência individual e coletiva, gerar conhecimento e potencializar a transformação de uma realidade. Tais características possuem relação direta com o uso estratégico da informação, 
ou seja, são traços característicos das práticas informacionais presentes na sociedade e nas organizações, e que podem ser alcançadas por intermédio da atuação mediadora dos processos de gestão, ora representados pelos modelos processuais da gestão da informação adotados pela Ciência da Informação.

$\mathrm{Na}$ gestão da informação, a modelagem dos processos é parte fundamental de uma sequência de etapas necessárias para a análise e a organização das práticas informacionais destinadas à otimização da capacidade de gestão das organizações.

O modelo permite a interligação de dados e informações que são fornecidos por meio de uma metodologia, mas serve essencialmente para comunicar algo em relação ao objeto da modelagem, de modo a suscitar um entendimento mais profícuo sobre a realidade que se deseja. "Eles podem ser considerados como aproximações seletivas que, pela eliminação de detalhes acidentais, permitem o aparecimento de alguns aspectos fundamentais relevantes ou interessantes do mundo real sob alguma forma generalizada" (SAYÃO, 2001, p. 84). O modelo possui uma natureza sugestiva, traz em si, ou seja, na inerência de sua estrutura, sugestões para a sua própria extensão e generalização.

Por fim, o uso de modelos permite construir uma ligação entre os níveis da observação e os níveis teóricos, além disso, desempenham uma função organizadora e lógica que contribui para explicar como ocorre determinado fenômeno. Dessa forma, adotou-se nesta pesquisa, para fins de análise, os modelos clássicos desenvolvidos por McGee e Prusak (1994), Davenport (1998) e Choo (2003).

Porém, levando em consideração a descrição e as principais características dos modelos citados, bem como a interpretação do pesquisador, o presente trabalho encontrou no modelo de GI formulado por Choo (2003), os requisitos técnicos, teóricos e pragmáticos necessários aos propósitos e objetivos estabelecidos para esta pesquisa. Tal interpretação reconhece no modelo de Choo (2003) os processos viáveis para a análise do uso estratégico da informação como elemento de integração e interação entre o sujeito usuário e o ambiente social e organizacional ao qual está inserido. 
Bruno de Araújo Ribeiro, Júlio Afonso Sá de Pinho Neto

Análise do processo de gestão da informação nos projetos artístico-culturais desenvolvidos pelo Centro Cultural Piollin

\section{PROCEDIMENTOS METODOLÓGICOS}

Esta pesquisa utilizou o método indutivo. Este método relaciona-se ao empirismo, ou seja, parte-se da premissa de que o conhecimento adquirido por meio deste método é fundamentado na experiência e na observação de fatos ou fenômenos cujas causas se deseja conhecer, sem levar em conta princípios preestabelecidos (GIL, 2002).

Quanto à natureza, o estudo caracteriza-se como sendo uma pesquisa aplicada e que faz uso de dois, dos três grandes grupos de classificação de pesquisa, o exploratório e o descritivo. Sob o tipo de abordagem, optou-se pelo uso de uma abordagem quantiqualitativa.

O universo de pesquisa foi formado por aqueles indivíduos que possuem uma relação direta com as atividades desenvolvidas por estas oficinas, e que pertencem aos seguintes públicos: Diretor, Coordenação Pedagógica, Educadores, Monitores e Educandos.

Para os públicos referentes ao Diretor, Coordenação Pedagógica, Educadores e Monitores, esta pesquisa utilizou o tipo de amostra não probabilística, cuja seleção dos participantes foi realizada por meio de critérios de intencionalidade, ou seja, "uma amostra intencional, em que os indivíduos são selecionados com base em certas características tidas como relevantes" (GIL, 2002, p. 145). Nessa etapa foram entrevistados cinco (05) participantes.

Já para o público dos Educandos, optou-se por uma amostra aleatória estratificada que contemplou de forma igualitária, os educandos oriundos das duas oficinas atualmente mantidas pelo Centro Piollin. Sendo assim, foram selecionados, aleatoriamente, $50 \%$ do total de educandos de duas oficinas (circo e teatro), chegando-se, desta maneira, a um total de 19 educandos pesquisados.

Em relação aos procedimentos de coleta de dados, para os objetivos deste estudo, optou-se, além do estudo de campo, pelo uso da pesquisa bibliográfica e da pesquisa documental. O levantamento bibliográfico, juntamente com a pesquisa documental, compôs a parte exploratória deste estudo e teve a finalidade de fornecer fundamentação teórica ao trabalho. 
Bruno de Araújo Ribeiro, Júlio Afonso Sá de Pinho Neto

Análise do processo de gestão da informação nos projetos artístico-culturais desenvolvidos pelo Centro Cultural Piollin

Para a fase de estudo de campo, optou-se pelo uso de entrevistas semiestruturadas como forma de coleta de dados junto aos públicos citados anteriormente. Tais instrumentos foram elaborados por meio do referencial de análise ofertado pelo modelo teórico de Gestão da Informação proposto por Chun Wei Choo (2003), representados pelas categorias dispostas no quadro abaixo e que foram foco da análise do processo de gestão da informação na realização das oficinas artísticas desenvolvidas e oferecidas pelo Centro.

Quadro 1 - Categorias de análise com base no modelo de Choo (2003).

\begin{tabular}{|c|c|c|c|c|c|}
\hline $\mathbf{1}^{\mathbf{a}}$ Categoria & $\mathbf{2}^{\mathbf{a}}$ Categoria & $\mathbf{3}^{\mathbf{a}}$ Categoria & $\mathbf{4}^{\mathbf{a}}$ Categoria \\
de informação & $\begin{array}{c}\text { Aquisição da } \\
\text { informação }\end{array}$ & $\begin{array}{c}\text { Organização e } \\
\text { armazenamento } \\
\text { da informação }\end{array}$ & $\begin{array}{c}\text { Desenvolviment } \\
\text { o de produtos e } \\
\text { serviços de } \\
\text { informação }\end{array}$ & $\begin{array}{c}\text { Distribuição da } \\
\text { informação }\end{array}$ & $\mathbf{6}^{\mathbf{a}}$ Categoria \\
\hline \multicolumn{5}{|c|}{$\begin{array}{c}\text { Uso da } \\
\text { informação }\end{array}$} \\
\hline $\begin{array}{c}\text { Indentificação das } \\
\text { necessidades de } \\
\text { informação }\end{array}$ & $\begin{array}{c}\text { Busca de } \\
\text { informação }\end{array}$ & $\begin{array}{c}\text { Classificação da } \\
\text { informação }\end{array}$ & $\begin{array}{c}\text { Identificação de } \\
\text { produtos e } \\
\text { serviços de } \\
\text { informação }\end{array}$ & $\begin{array}{c}\text { Procedimentos } \\
\text { de distribuição } \\
\text { da informação }\end{array}$ & $\begin{array}{c}\text { Analisar o uso } \\
\text { da informação }\end{array}$ \\
\hline $\begin{array}{c}\text { Relevância das } \\
\text { informaçães } \\
\text { necessitadas }\end{array}$ & $\begin{array}{c}\text { Fontes de } \\
\text { informação }\end{array}$ & $\begin{array}{c}\text { Procedimentos } \\
\text { de } \\
\text { armazenamento } \\
\text { da informação }\end{array}$ & $\begin{array}{c}\text { Compartilhament } \\
\text { o da informação }\end{array}$ & $\begin{array}{c}\text { Identificar a } \\
\text { assimilação da } \\
\text { informação }\end{array}$ \\
\hline & $\begin{array}{c}\text { Barreiras de } \\
\text { busca na } \\
\text { informação }\end{array}$ & & & & \\
\hline
\end{tabular}

Fonte: Elaborado pelos autores (2016).

Os critérios de categorização estabelecidos, que foram parte da fase exploratória, foram extraídos do modelo de gestão da informação proposto por Choo (2003), que como já justificado anteriormente, correspondeu ao modelo mais indicado para utilização nesta pesquisa. Após a coleta, o passo seguinte foi o de analisar e interpretar os dados obtidos. Destarte, para o presente trabalho optou-se pela análise temática subscrita na Análise de Conteúdo ( $A C)$ de Laurence Bardin.

\section{ANÁLISE DOS DADOS}

Para identificar as falas utilizou-se uma sequência de códigos escolhidos aleatoriamente. São eles: D (Diretor) e C (coordenadora pedagógica). No caso dos educadores e educandos, utilizaram-se respectivamente os códigos "E" para educadores e "EN" para educandos, ambos acrescidos de números para 
Bruno de Araújo Ribeiro, Júlio Afonso Sá de Pinho Neto

Análise do processo de gestão da informação nos projetos artístico-culturais

desenvolvidos pelo Centro Cultural Piollin

diferenciar cada um dos participantes desta população, por exemplo: E1, E2, etc., EN1, EN2, etc.

\subsection{Categoria 1: Necessidades de informação}

No Centro Piollin, as necessidades de informação obedecem a duas situações específicas, uma nascida das ações pedagógicas, voltadas para a consecução das oficinas conduzidas pela equipe pedagógica (coordenadora e educadores), e outra que emerge da experiência individual vivenciada por cada um dos educandos, ou seja, surgem decorrentes de situações e dos estímulos produzidos pelas atividades que cada um destes desempenha individualmente nas duas oficinas atualmente ofertadas pelo Centro. O que deve se evidenciar é que, tanto a equipe pedagógica quanto os educandos possuem necessidades de informação específicas, muitas vezes distintas e que surgem de situações nem sempre coincidentes.

Nas oficinas do Piollin, as situações em que há necessidade de informação podem ser descritas pela natureza das atividades conduzidas e ministradas em tais oficinas, principalmente no que diz respeito àqueles valores que vão além das atividades práticas em si, e que estabelecem os critérios pelos quais é possível julgar a importância de uma informação para determinada situação. Tais valores dizem respeito ao que subjaz a prática de tais oficinas, que estão voltadas intricadamente para o exercício da cidadania e para promover uma transformação na vida dessas pessoas. Dessa forma, procurou-se levantar a natureza dessas atividades e de que forma elas se integram aos objetivos finais das oficinas.

Em mais de uma oportunidade, pôde-se perceber que os objetivos a que se pretendem tais oficinas, não se limitam apenas às atividades técnicas e lúdicas do circo ou do teatro, mas possuem a clara intenção de propor algo muito mais abrangente, visando contemplar o indivíduo enquanto cidadão, trabalhando o seu convívio em grupo e sua relação com a sociedade. Segundo o relato da Coordenadora pedagógica, "todas as atividades têm cunho social. Elas partem de um tema gerador, por exemplo, se a gente quer discutir família, sociedade de forma geral, então na aula de teatro, a professora utiliza metodologicamente atividades que envolvam e discutam esses temas". Essa 
Bruno de Araújo Ribeiro, Júlio Afonso Sá de Pinho Neto

Análise do processo de gestão da informação nos projetos artístico-culturais

desenvolvidos pelo Centro Cultural Piollin

concepção também é perceptível na fala de um dos educadores ( $E 1)$, quando este afirma que, "a gente tem um sistema que se chama circuito temático que busca trazer temas que estão envolvidos no nosso dia-a-dia, porém, nosso objetivo maior vai além da técnica, é o círculo social".

Nesse contexto, as atividades desenvolvidas tornam-se meios para a obtenção dos objetivos almejados pelas oficinas do Centro, e não fins, como uma leitura apressada poderia sugerir. A condução das atividades por meio de um eixo temático capaz de envolver, por exemplo, a educação para a cidadania permite não só uma interação mais profícua entre os educandos, mas também estimula de forma colaborativa a troca de experiências tácitas. Nesse sentido, o Piollin busca, através de suas oficinas, estimular uma mudança de comportamento nos educandos, fazendo com que estes se percebam como indivíduos participantes de uma coletividade, sendo eles capazes de buscar seus direitos, sua liberdade, melhores garantias individuais e coletivas, ou seja, indo além do ensino de técnicas e de atividades lúdicas, para contribuir de forma mais ampla com uma formação cidadã.

Assim como já foi dito, as necessidades de informação surgem de situações e dos estímulos das atividades desenvolvidas nas oficinas, ou seja, surgem em decorrência dessas atividades, dos questionamentos que daí emergem, da forma como essas atividades são conduzidas, do interesse pessoal e coletivo dos seus participantes e da forma como cada um dos educandos tem acesso aos ensinamentos.

Já para a equipe pedagógica (coordenação e educadores), os interesses e necessidades de informação estão relacionadas e direcionadas para o planejamento das oficinas e de suas atividades, contemplando assim aquelas informações que vão contribuir para a elaboração e desenvolvimento das atividades lúdicas, incluindo-se aí o ensino de técnicas e a realização de um aprendizado a partir de atividades práticas, sempre de forma coletiva.

Já no que se refere à natureza social e educativa das oficinas (ressaltando-se aqui a educação para a cidadania), a pesquisa procurou levantar de que forma e sob quais aspectos essas dimensões são exploradas. Para tanto, utilizou-se, por intermédio dos instrumentos de coleta de dados, 
Bruno de Araújo Ribeiro, Júlio Afonso Sá de Pinho Neto

Análise do processo de gestão da informação nos projetos artístico-culturais desenvolvidos pelo Centro Cultural Piollin

temas-chave capazes de representar essas dimensões e que pudessem também gerar correlações com os temas trabalhados nas oficinas.

Gráfico 1 - Linhas orientadoras da educação para a cidadania (educandos).

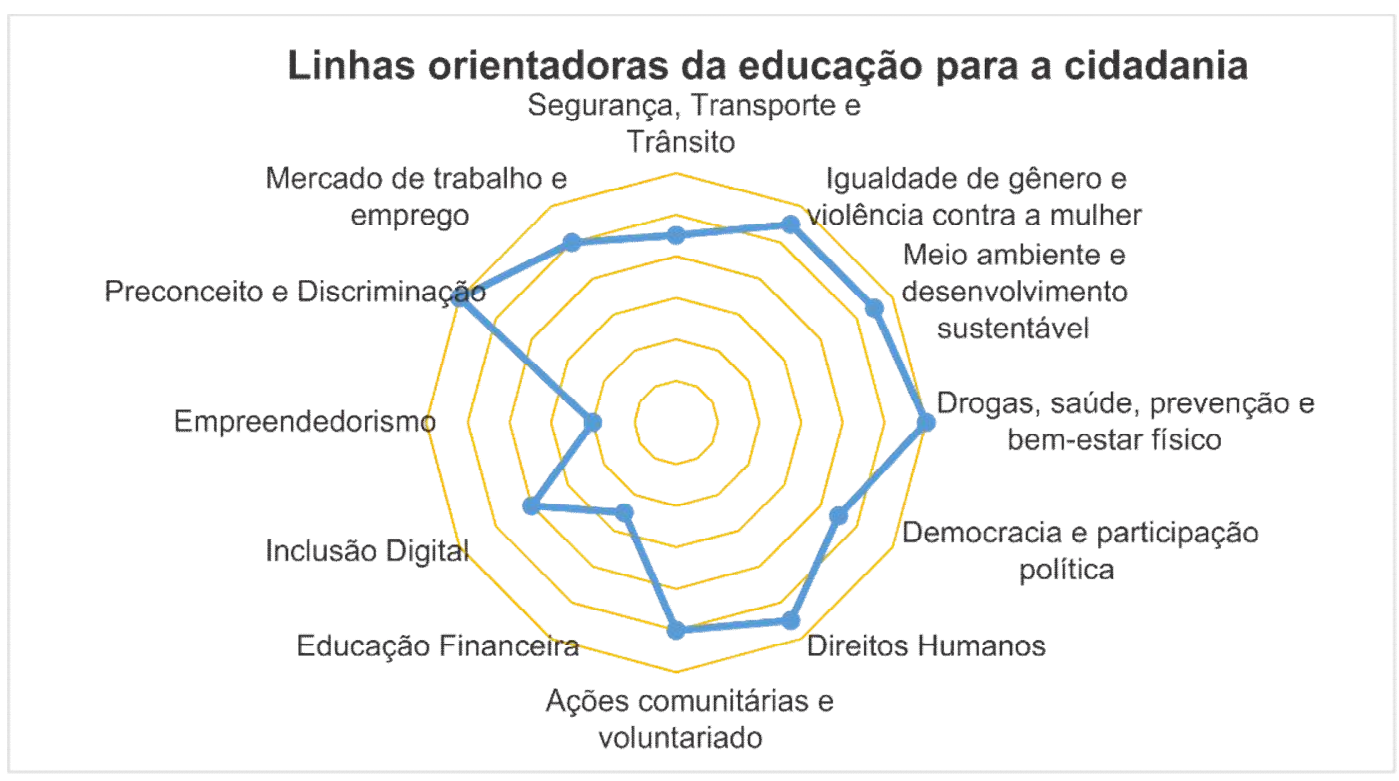

Fonte: Elaborado pelos autores (2016).

No gráfico 1, as linhas orientadoras mais mencionadas pelos educandos são aquelas que se aproximam da borda do círculo, ou seja, quanto maior o número de citações sobre cada tema, mais os pontos se aproximam da borda externa do círculo. Destes, os mais citados, pela ordem, são: Preconceito e Discriminação (12); Drogas, saúde, prevenção e bem-estar físico (12); Igualdade de gênero e violência contra a mulher (11); Meio ambiente e desenvolvimento sustentável (11); Direitos Humanos (11); Ações comunitárias e voluntariado (10); Mercado de trabalho e emprego (10); Democracia e participação política (9); Inclusão Digital (8); Educação Financeira (5) e Empreendedorismo (4). De acordo com os educandos, todos os temas citados foram de alguma forma trabalhados pelo Centro.

Como é possível perceber, essas linhas de orientação podem assumir uma variedade de formas, evidentemente todas elas procuram estar em conformidade com as dinâmicas adotadas pelo Centro, visando o objetivo precípuo das oficinas ali oferecidas que é, antes de mais nada, a de promover

Inf. Inf., Londrina, v. 21, n. 3, p. 258 - 285, set./dez., 2016. 
Bruno de Araújo Ribeiro, Júlio Afonso Sá de Pinho Neto

Análise do processo de gestão da informação nos projetos artístico-culturais desenvolvidos pelo Centro Cultural Piollin

a educação para a cidadania. Fato que pode ser percebido no trecho do educador (E2), quando este explica como as linhas orientadoras são trabalhadas nas oficinas: "os temas são trabalhados sempre na forma de circuitos temáticos, os alunos participam de atividades específicas, tais como palestras, assistem vídeos, filmes, e são feitos jogos e debates entre eles sobre o tema decorrido". Sendo assim, percebe-se, por meio das informações apresentadas e discutidas acima, as necessidades de informação provenientes das oficinas desenvolvidas pelo Centro Cultural Piollin.

\subsection{Categoria 2: Busca e Aquisição da informação}

A pesquisa revelou que, durante o processo de busca, os educandos do Piollin obtêm informações de muitas e diferentes fontes, formais e informais. As fontes informais geralmente estão relacionadas aos próprios colegas do Centro ou a contatos pessoais, e podem ser assim consideradas, na medida em que se percebe que entre eles é mantido um fluxo constante de troca de informações e de conteúdos relacionados às atividades ali praticadas. Já as fontes formais são provenientes do próprio Centro, das atividades e do conteúdo programático presente na proposta pedagógica das oficinas. Tais fontes também são representadas pelos educadores, pela coordenadora pedagógica e pelos demais facilitadores do Centro.

Essa observação é percebida através da fala do diretor (D), quando este afirma que o Piollin possui uma ação voltada para permitir que os educandos tenham acesso a tipos variados de informações, diz ele: "nós temos uma ação de acesso às produções, que a gente chama de acesso às produções artísticas, aos espetáculos, a visitações em exposições, isso é uma forma de você ver coisas de fora". O diretor também afirma que são vários os eventos e encontros realizados fora do Piollin, onde é possível viabilizar a participação dos educandos e da equipe pedagógica, para que estes possam ter acesso participando como espectadores e conhecendo as atividades ali desenvolvidas. "Por exemplo, o circo de Soleil [...] estabelece uma parceria com várias escolas que trabalham com o chamado circo social, que é o nosso caso [...] em Recife teve um espetáculo e a gente levou os alunos para conhecer". 
Bruno de Araújo Ribeiro, Júlio Afonso Sá de Pinho Neto

Análise do processo de gestão da informação nos projetos artístico-culturais desenvolvidos pelo Centro Cultural Piollin

Os principais meios de busca de informação identificados e utilizados pelos educandos e pela equipe pedagógica foram a internet, os livros e revistas com literatura relacionada às atividades, os eventos artístico-culturais locais e os contatos com pessoas do meio artístico. Esses meios de busca dão acesso a vários tipos de fontes informação, como por exemplo, aquelas provenientes do próprio Centro e que são representadas pelos educadores e demais facilitadores. Outras fontes são representadas pelos espetáculos artísticos externos, perfis de mídias sociais, vídeos, blogs e sites relacionados às atividades realizadas nas oficinas.

\subsection{Categoria 3: Organização e armazenamento da informação}

Durante a pesquisa de campo, percebeu-se que no Centro Piollin, uma das principais formas de armazenar informações é realizada por intermédio de suas avaliações semestrais, realizadas sempre no final dos semestres e direcionadas aos educandos. Tais avaliações procuram levantar questionamentos, dúvidas e opiniões acerca das atividades que foram desenvolvidas naquele período. O Centro utiliza diversas metodologias que procuram estimular os educandos a expressarem suas principais opiniões. Os pesquisadores, em uma das idas a campo, tiveram a oportunidade de presenciar uma dessas avaliações e acompanhar a dinâmica que foi ali aplicada. Tratava-se de uma "roda de conversa" onde todos os educandos participavam expressando suas opiniões e avaliando as atividades realizadas nas oficinas. A avaliação foi conduzida pela coordenadora pedagógica e por um dos educadores que registrou em um diário todas as opiniões e avaliações advindas dos educandos.

A recuperação de interpretações passadas é uma das formas utilizadas pelo Centro para dar significado a uma experiência atual, ou seja, as informações e interpretações armazenadas assumem a forma de registros ou mapas causais que podem ser conservados pelos indivíduos mentalmente ou por intermédio de registros físicos. Quando necessário, esses indivíduos podem invocar essas interpretações em forma de mapas retrospectivos, histórias ou por meio de uma narrativa, permitindo assim que situações e fatos anteriores possam ser vivenciados novamente. No caso do Piollin, todas as 
Bruno de Araújo Ribeiro, Júlio Afonso Sá de Pinho Neto

Análise do processo de gestão da informação nos projetos artístico-culturais

desenvolvidos pelo Centro Cultural Piollin

informações colhidas nessas avaliações são armazenadas para dar suporte a um futuro planejamento das atividades. Desse modo, percebe-se que as opiniões e sugestões produzidas por meio dessas avaliações são informações que funcionam não apenas como instrumento de memória, mas como um símbolo de um aprendizado tácito vivenciado pelos educandos, educadores e todos os demais facilitadores das oficinas do Piollin.

\subsection{Categoria 4: Produtos e serviços de informação}

Esta categoria procurou identificar quais os produtos e serviços de informação que são utilizados e desenvolvidos pelo Piollin. Tais produtos e serviços dão suporte às ações e atividades desenvolvidas pelo Centro e estabelecem os instrumentos formais adotados capazes de agregar valor à informação, de modo que esta, quando ali disponibilizada, seja melhor aproveitada por seus usuários.

A pesquisa identificou os principais produtos e serviços desenvolvidos e ou utilizados pelo Centro. Entre os principais produtos de informação estão o quadro de avisos utilizado para alguns comunicados, mas também para divulgar espetáculos e outras atividades artísticas externas ao Centro; entre os outros produtos estão vídeos e livros com literatura específica sobre circo e teatro. Já quanto aos serviços, os que possuem maior destaque são o "Boa Tarde", que consiste numa roda de discussão onde os educadores falam sobre as atividades que serão realizadas no dia e os educandos têm a possibilidade de dialogar sobre questões relativas a essas atividades, expressando suas opiniões, fazendo sugestões e esclarecendo dúvidas. Complementando tais serviços, há uma biblioteca, que possui um extenso acervo de livros e revistas da área de circo e teatro, além de outros gêneros literários. Por último, tem-se o uso das mídias sociais (Facebook e WhatsApp), algo bastante recorrente na troca de informações sobre as atividades das oficinas, como também para realizar os comunicados do Centro que se fazem necessários. Enquanto ativa e contando com uma bibliotecária, o espaço servia para estimular a leitura dos educandos e para dar suporte às atividades realizadas nas oficinas.

Tal situação mostra que os produtos de informação da biblioteca não estão abertos e disponíveis a qualquer momento para os educandos, estes 
Bruno de Araújo Ribeiro, Júlio Afonso Sá de Pinho Neto

Análise do processo de gestão da informação nos projetos artístico-culturais desenvolvidos pelo Centro Cultural Piollin

somente são utilizados quando os educadores resgatam o material para trabalhá-los especificamente em determinadas atividades, ou então quando os educandos solicitam o uso de determinado título de livro. Dessa forma, tal deficiência faz com que este produto de informação esteja comprometido no que diz respeito ao seu potencial de uso, tendo em vista que o objetivo da biblioteca é, antes de mais nada, o de permitir o contínuo acesso à busca de informação.

Nesse sentido, percebe-se atualmente que devido às circunstâncias financeiras do Centro, alguns dos produtos e serviços de informação identificados pela pesquisa são utilizados sem planejamento, com exceção do "Boa tarde". Os educandos fazem uso das mídias sociais de uma forma completamente alheia a qualquer processo de gestão, elas são utilizadas pelos educandos de uma forma não planejada; a biblioteca não conta com um profissional específico e habilitado que viabilize a livre pesquisa e consulta pelos educandos; o quadro de avisos não atende a critérios que possam estabelecer uma pauta e uma periodicidade das informações que serão ali veiculadas. Nesse sentido, tais produtos e serviços necessitam de uma gestão e de um planejamento que permitam criar mecanismos para que as pessoas possam expressar as demandas de informação que irão alimentar tais instrumentos, de modo que estes possam atender eficazmente suas necessidades de informação.

\subsection{Categoria 5: Distribuição da informação}

Essa categoria procurou identificar os procedimentos de distribuição e compartilhamento da informação adotados pelos educandos e pela equipe pedagógica no desenvolvimento das atividades realizadas nas oficinas.

O processo de distribuição da informação é notadamente o meio pelo qual a informação é distribuída pela organização, de modo que, após processada e disponibilizada por intermédio de produtos e serviços, essa informação possa atingir o indivíduo no momento certo, no lugar e no formato adequado. A disponibilização da informação antecede o seu uso, e ocorre por 
Bruno de Araújo Ribeiro, Júlio Afonso Sá de Pinho Neto

Análise do processo de gestão da informação nos projetos artístico-culturais desenvolvidos pelo Centro Cultural Piollin

meio dos "canais" de disseminação e distribuição adotados pela organização, sendo que estes, por sua vez, podem ser formais e informais.

Nas oficinas, a distribuição e o compartilhamento de informações estão voltados para três aspectos prioritários, o primeiro deles refere-se às informações oriundas das atividades pedagógicas direcionadas às oficinas; o segundo está relacionado às informações sobre os eventos referentes à programação artístico-cultural local, ou seja, como os educandos e a equipe pedagógica compartilham informações visando divulgar e estimular a participação dos educandos em tais eventos culturais; e, por fim, o terceiro aspecto, que se refere às informações oriundas das atividades prediletas desenvolvidas por cada um dos educandos, ou seja, do compartilhamento de informações que surgem a partir da aprendizagem de atividades específicas, como por exemplo, o trapézio, o malabares, as acrobacias de solo, a lira e o tecido.

Apesar da biblioteca do Centro funcionar atualmente de modo parcial, no planejamento das atividades pedagógicas, o material proveniente daquele espaço (livros, revistas e textos) geralmente é utilizado para dar suporte às atividades realizadas nas oficinas, assim como pode ser visto nos depoimentos do diretor (D) e do educador (E2), respectivamente: "Há compartilhamento por meio do acervo da biblioteca ou pela confecção de cópias de material disponível na internet, dentre outros meios"; "Trabalha-se sempre na indicação de livros da biblioteca e vídeos na internet". Contudo, conforme foi abordado anteriormente, ainda que tal conteúdo não esteja disponível em sua plenitude, este conteúdo é compartilhado indiretamente a partir do que os educadores recomendam nas oficinas.

A presença desse mesmo discurso nos depoimentos dos educandos referenda essa prática de compartilhamento no Piollin. É o que pode ser visto por meio do depoimento do educando (EN8), ao afirmar que parte do compartilhamento ocorre "pelos livros que eles passam, o professor foca em algum aluno quando vê que ele tem mais interesse, aí ele entrega aquele livro para o aluno pesquisar mais". 
Bruno de Araújo Ribeiro, Júlio Afonso Sá de Pinho Neto

Análise do processo de gestão da informação nos projetos artístico-culturais desenvolvidos pelo Centro Cultural Piollin

No que concerne ao compartilhamento de informação em função das atividades preferidas dos educandos, este é realizado de forma mais aleatória e informal, sem obedecer a nenhum plano de ação, ou que utilize produtos ou serviços de informação específicos para tal. Esse compartilhamento é espontâneo e depende basicamente dos interesses específicos de cada um dos educados em relação às atividades realizadas. Por mais que haja a presença da equipe pedagógica nessa interação, as informações compartilhadas partem geralmente de estímulos individuais que podem ou não se estender a todo o grupo.

É importante ressaltar que os indivíduos necessitam de um fluxo contínuo de informações, interno e externo, capaz de fornecer informações relevantes, com o objetivo de atender às necessidades de informações, esclarecer ambiguidades, preencher lacunas, atualizar interpretações e obter respostas acerca de um problema.

\subsection{Categoria 6: Uso da informação}

Nas oficinas, todo o conjunto de informações que circundam o planejamento e a realização das atividades é utilizado basicamente para dar suporte teórico e pedagógico à consecução de tais atividades. Vale ressaltar ainda que, por mais que não estejam explícitos nos depoimentos coletados, as atividades desenvolvidas nas oficinas priorizam o princípio da arte-educação que, como afirma Barbosa (2005 apud DAL GALLO, 2010), é um meio eficaz na promoção do desenvolvimento de crianças e adolescentes, por meio de linguagens artísticas, predominantemente as artes circenses, que são utilizadas como um canal de integração e expressão, de promoção da cidadania e de transformação social, ou seja, as oficinas fazem uso de uma linguagem artística com o objetivo de formar cidadãos. Prova disso, é o trecho extraído do depoimento da coordenadora (C), quando esta afirma que, "a gente precisa construir cidadãos pensantes, que discutam, questionem sua realidade e que tenham a liberdade de exercer o seu papel de cidadãos mesmo".

Nesse contexto, o uso da informação é dirigido a três pontos fundamentais: o primeiro envolve o desenvolvimento do senso político dos educandos, no que diz respeito aos seus direitos individuais enquanto 
Bruno de Araújo Ribeiro, Júlio Afonso Sá de Pinho Neto

Análise do processo de gestão da informação nos projetos artístico-culturais desenvolvidos pelo Centro Cultural Piollin

cidadãos, sendo necessário, para tanto, trabalhar linhas de orientação que possam atender a essas demandas; já o segundo diz respeito à formação artística dos educandos, que ocorre por intermédio do desenvolvimento de suas habilidades e do seu próprio potencial, como também pelo conjunto de ações complementares que ladeiam essas atividades e, por último, o terceiro ponto, que está relacionado ao ensino e ao exercício de práticas que permitam aos educandos se organizarem com objetivos comunitários direcionados a resolver problemas do cotidiano coletivo, e que se traduz no processo de educação para a cidadania.

Ainda segundo Dal Gallo (2010, p. 27), e levando em conta tais propósitos, a arte-educação torna-se uma prática pedagógica pela qual, por meio do ensino de técnicas circenses e de teatro, é possível desenvolver valores e capacidades que derivam do exercício prático das atividades, como por exemplo, "o respeito, a mútua confiança, a atenção pelos outros e pela segurança, o autocontrole, entre outras. Além disso, através do circo, é possível transmitir informações e noções sobre a cultura, que podem ser internas ou externas ao contexto dos alunos".

Nesse sentido, o Centro foi pensado para atuar como um espaço social capaz de utilizar a formação artística como um instrumento de educação não formal, contribuindo assim para criar um ambiente alternativo de socialização, lazer e cultura. Sob essa perspectiva, os educandos devem aprender a dialogar com o ambiente no qual estão inseridos, com a realidade de seus colegas e com os problemas cotidianos que se apresentam (DAL GALLO, 2010). Tal observação pode ser evidenciada ainda no depoimento da coordenadora (C), quando esta afirma que os educandos, por intermédio das atividades, conseguem desenvolver habilidades sociais. "Aqui eles desenvolvem habilidades sociais, tratar melhor o outro, tentar e compreender o outro e compreender melhor o mundo". Tal depoimento relaciona-se também com o depoimento do educando (EN8), quando este relata sua experiência de aprendizagem no Piollin: "Aqui no Centro eu aprendi muita coisa, convivência, respeito com as pessoas, muitas coisas, tipo, não jogar lixo na rua". 
Bruno de Araújo Ribeiro, Júlio Afonso Sá de Pinho Neto

Análise do processo de gestão da informação nos projetos artístico-culturais desenvolvidos pelo Centro Cultural Piollin

Um outro momento de uso da informação está relacionado às produções artísticas que são desenvolvidas e protagonizadas pelos próprios educandos, e que consistem na elaboração de espetáculos cênicos, direcionados a um público diversificado, como por exemplo, as comunidades do entorno do Piollin, outras Organizações Não Governamentais, além de escolas públicas da região metropolitana de João Pessoa - PB e de outras cidades do interior da Paraíba. Essa iniciativa compõe uma das ações mais conhecidas do Centro e é chamada de "Caravana Piollin". Trata-se de uma ação que, além de promover o trabalho artístico do Piollin, também oportuniza aos educandos uma experiência prática, de modo que eles possam apresentar ao público dessas localidades, as habilidades conquistadas durante o curso das oficinas. De acordo com o relato do diretor do Centro, "a Caravana Piollin possibilita apresentações em cidades do interior e bairros de João Pessoa-PB. Esse projeto potencializa o protagonismo e exercita a produção artística dos educandos, além do conhecimento da história e geografia dessas cidades que eles conhecem".

Dessa forma, o resultado do uso da informação nesse contexto é o de promover uma mudança no estado de conhecimento desses educandos por meio de uma experiência que utiliza a formação e a prática artística como instrumento complementar à educação para a cidadania e que, consequentemente, produz também uma nova capacidade de ação nesses sujeitos. Nesse sentido, a informação é usada para esclarecer, gerar compreensão, desenvolver uma ação, descrever uma realidade, promover o senso crítico, projetar cenários, despertar interesses e gerar um comportamento proativo diante dos desafios e dificuldades a serem enfrentados.

\section{CONSIDERAÇÕES FINAIS}

Como foi possível constatar durante toda a análise, as necessidades de informação que emergem das oficinas obedecem a duas situações específicas, a primeira delas está relacionada às atividades pedagógicas, ou seja, surgem do desenvolvimento das atividades que abrigam, conforme o planejamento das 
Bruno de Araújo Ribeiro, Júlio Afonso Sá de Pinho Neto

Análise do processo de gestão da informação nos projetos artístico-culturais desenvolvidos pelo Centro Cultural Piollin

oficinas, as situações propícias à aprendizagem dos educandos, levando em conta os conteúdos (artísticos ou educativos) a serem transmitidos e a melhor maneira de fazê-lo. A segunda situação de necessidade diz respeito à experiência prática e lúdica vivida pelos educandos. Tal necessidade de informação é basicamente decorrente dos estímulos produzidos pelas atividades que cada um destes desempenha individualmente nas oficinas. Vale ressaltar que, tais situações de necessidade obedecem à dinâmica de funcionamento das próprias oficinas, ou seja, têm início por meio do ensino de técnicas artísticas de circo e de teatro, dirigindo-se, posteriormente, às atividades pedagógicas que contemplam conteúdos específicos para as discussões comuns entre os educandos, como por exemplo, os conteúdos e temas que promovem o processo de educação para a cidadania.

Tal ressalva é necessária, pois, como já foi mencionado, as atividades desenvolvidas nas oficinas aproximam-se do princípio da arte-educação, conforme define Barbosa (2005 apud DAL GALLO, 2010), ou seja, as oficinas fazem uso de uma linguagem artística como forma de promover a conscientização social, a descoberta dos direitos e das obrigações dos educandos.

Contudo, por mais que tais necessidades tenham sido identificadas da forma como se descreveu acima, no Centro Piollin, os sujeitos envolvidos com as oficinas ainda não possuem uma visão clara sobre essas necessidades, evidenciando-se assim, mais uma vez, a importância de se trabalhar a gestão da informação nesse contexto. Nesse sentido, por mais que o Centro tenha uma preocupação em alinhar tais necessidades às práticas pedagógicas das oficinas, é perceptível que há certa dificuldade nesse processo, principalmente quando se trata das necessidades de informação que estão direcionadas à promoção de uma educação para a cidadania, tento em vista que este é um dos objetivos fundamentais das oficinas e do Piollin. Dessa forma, tal objetivo de educar para a cidadania gera uma demanda específica de informação, informação essa, que será capaz de complementar a formação prática e artística, com um embasamento que irá convergir para a melhoria da qualidade de vida, para a conscientização política do indivíduo e para o desenvolvimento 
Bruno de Araújo Ribeiro, Júlio Afonso Sá de Pinho Neto

Análise do processo de gestão da informação nos projetos artístico-culturais desenvolvidos pelo Centro Cultural Piollin

de uma atitude crítica e reflexiva diante do contexto social no qual ele está inserido.

Dessa forma, o Centro carece de um processo de gestão que priorize tais necessidades, possibilitando a consecução aos objetivos almejados pelas oficinas. Por mais que vários dos aspectos desses objetivos estejam presentes no discurso proferido pela equipe pedagógica, estes não se realizam plenamente na prática, haja vista que além das dificuldades observadas na categoria das necessidades de informação, o Centro também possui carências de outras naturezas. Destarte, conforme foi observado, não há uma estrutura própria naquele espaço com a finalidade de estabelecer meios capazes de dar maior acesso à informação, como por exemplo, um laboratório de informática com acesso à internet, com o objetivo de facilitar, principalmente por parte dos educandos, a busca e aquisição da informação. Todavia, vale salientar que por mais que haja um estímulo por parte dos educadores para que os educandos busquem informações, esta é quase sempre realizada sem o acompanhamento necessário, fundamental para direcionar os educandos às informações que realmente estejam alinhadas com os propósitos das oficinas, pois, sem o devido apoio e direcionamento, a busca estará direcionada apenas aos interesses individuais momentâneos destes educandos.

Nesse sentido, torna-se extremamente necessário ao Piollin, no que diz respeito às oficinas oferecidas, que estabeleça diretrizes que elevem a gestão da informação a um patamar estratégico, pois assim como foi evidenciado, os produtos e serviços de informação disponíveis atualmente não atendem de forma satisfatória às necessidades de busca e de informação ali identificadas, algo que por si só já demandaria grande preocupação, pois os produtos e serviços devem funcionar como instrumentos que explorem o potencial e a utilidade que a informação disponibilizada é capaz de gerar nesses educandos. Contudo, o que se percebe é que os produtos e serviços ali existentes agregam pouco valor à informação, tendo em vista que tais mecanismos não são gerenciados verdadeiramente como deveriam, ou seja, o uso destes ocorre sem o devido planejamento. Como exemplo, pode-se citar as mídias sociais, que são utilizadas completamente dissociadas de qualquer planejamento, 
Bruno de Araújo Ribeiro, Júlio Afonso Sá de Pinho Neto

Análise do processo de gestão da informação nos projetos artístico-culturais desenvolvidos pelo Centro Cultural Piollin

ficando seu uso a cargo da vontade individual de cada um dos educandos, ou mesmo o quadro de avisos, que vem funcionando apenas como um espaço de divulgação de conteúdos informais, que não obedecem a critérios prédefinidos, com o objetivo de abordar as informações que poderiam ser verdadeiramente relevantes.

Ainda sobre esse aspecto, tem-se a biblioteca, que não conta com um profissional especializado, com a função de viabilizar plenamente o uso daquele espaço para os educandos. Nesse sentido, a utilização dos produtos de informação da biblioteca é realizada de forma pontual, não planejada, sem contar com o incentivo e o estímulo à leitura que um profissional da área seria capaz de fomentar nesses indivíduos. Isto porque, os livros não estão disponíveis a qualquer momento, fazendo com que este serviço fique comprometido no que diz respeito ao seu potencial de uso, uma vez que o objetivo da biblioteca é, antes de tudo, o de permitir o acesso à informação e auxiliar os educandos no uso adequado dos produtos de informação oriundos daquele espaço.

Destarte, é notadamente perceptível a necessidade de qualificar pessoas que sejam capazes de gerenciar tais produtos e serviços no Centro, de modo que o acesso a estes produtos possa ocorrer de forma planejada, exigindo, posteriormente, a realização de um estudo amplo que permita conhecer melhor o perfil de cada um dos educandos e suas reais demandas de informação. Dessa forma, os produtos e serviços estariam alinhados às necessidades de informação que verdadeiramente possam contribuir para a consecução dos objetivos previstos para as oficinas, e não apenas para atender demandas segmentadas, pontuais e específicas, frutos da mera interação individual dos educandos com as atividades que cada um realiza nas oficinas. Para tanto, é necessário que esses produtos e serviços facilitem o uso da informação, reduzam os ruídos, agreguem valor à informação, promovam a adaptabilidade de seu uso, a economia de tempo e o custo emocional que é desprendido no processo de busca da informação.

A ausência desse tipo de gestão provoca carências e lacunas que podem influenciar no resultado que se procura alcançar com a realização 
Bruno de Araújo Ribeiro, Júlio Afonso Sá de Pinho Neto

Análise do processo de gestão da informação nos projetos artístico-culturais desenvolvidos pelo Centro Cultural Piollin

dessas oficinas; ou seja, mesmo que o Piollin consiga atingir parcialmente seus objetivos no que diz respeito à experiência das oficinas, como foi constatado na pesquisa de campo, tais lacunas terminam por subtrair os benefícios que sua proposta seria capaz de trazer aos educandos, pois à medida que seja possível promover um trabalho de gestão da informação que contemple, de forma integrada e planejada, todas essa categorias, o Piollin poderá de fato capacitar os educandos a conhecer melhor suas necessidades de informação. Paralelamente a isto, serão estabelecidas estratégias como o objetivo de capacitar os educandos a buscarem, de maneira livre e proativa, as informações que efetivamente possam atender às suas demandas. Dessa forma, o Centro não só estará melhorando a gestão de suas oficinas, como também estará colaborando verdadeiramente para a educação para a cidadania.

Contudo, percebeu-se que grande parte das informações ali trabalhadas chegam sempre ao educando de forma tutelada, ou seja, são recebidas de forma segmentada e, na maioria das vezes, estão sempre direcionadas a interesses pontuais e específicos, como por exemplo, a indicação prédeterminada de livros pelos educadores, o uso de determinado material nas atividades pedagógicas, ou até mesmo o compartilhamento de certas fontes e conteúdos via mídias sociais, estas últimas, inclusive, figuram como as únicas formas que os educandos possuem para realizar a busca e o compartilhamento das informações. Dessa forma, o Piollin deveria atuar exatamente no sentido de reverter tal quadro; ou seja, ao atender - a partir de um processo de gestão da informação - tais demandas, o Piollin estará estimulando um aprendizado mais profícuo, pois dessa forma estará viabilizando, de forma profissional e planejada, o compartilhamento, a distribuição, o armazenamento e o uso da informação, um processo essencial à aquisição de conhecimentos e à educação para a cidadania.

Em todos os aspectos, a aplicação da gestão da informação a partir das atividades realizadas nas oficinas do Piollin torna-se essencial para a formação de um "senso político" nos educandos, contribuindo, assim, para a sua formação artística e cultural a partir de uma conscientização e educação para a 
Bruno de Araújo Ribeiro, Júlio Afonso Sá de Pinho Neto

Análise do processo de gestão da informação nos projetos artístico-culturais desenvolvidos pelo Centro Cultural Piollin

cidadania. Tal situação viabilizará, ainda, uma organização coletiva dos educandos, capaz de prepará-los para detectarem problemas e objetivos comuns relacionados ao seu cotidiano na comunidade onde pertencem. Isto os tornará aptos à mobilização política visando a melhoria de sua qualidade de vida. Um bom exemplo disso é o protagonismo que tais educandos podem vir a exercer, caso o Centro venha a adotar esse tipo de gestão, na realização da "Caravana Piollin", ocasião onde são realizadas as apresentações artísticas após a finalização de cada oficina, tendo em vista que os espetáculos que integram essa ação compõem uma parte importante do processo de ensino e aprendizagem, contribuindo sobremaneira na formação desses educandos.

Em função desses aspectos, pode-se dizer que é necessário explorar a função essencial que subjaz à organização das oficinas e de suas dinâmicas, que é levar a prática do aprendizado de determinadas atividades artísticas a fazer parte de um processo pedagógico, preocupado não apenas com a forma como tais atividades são ministradas, mas também como estas são assimiladas e apropriadas pelos educandos tendo em vista a sua formação cidadã.

Nesse sentido, para que tais resultados sejam alcançados, a gestão da informação cumpre também outra função, que é a de justamente gerar a reflexão necessária, a partir dos resultados obtidos e através da consecução dessas oficinas para a necessidade de realizar uma organização e mobilização comunitária, ou seja, ela é capaz de fazer com que os educandos venham a perceber e valorizar suas conquistas sob uma ótica comunitária, reforçando, assim, os esforços e a mobilização no sentido do exercício da cidadania.

Dessa maneira, a gestão da informação torna-se um elemento-chave no auxílio e na consecução dos objetivos das oficinas e, consequentemente, do próprio Centro Piollin, pois tem a competência de estabelecer, por meio do uso planejado da informação, um ambiente que estimule o envolvimento e o compromisso dos educandos com a transformação da sua realidade de vida.

Portanto, a gestão da informação, no contexto das oficinas, se faz extremamente necessária, pois será capaz de atuar no sentido de combater todas as carências e lacunas existentes em matéria de informação identificadas 
Bruno de Araújo Ribeiro, Júlio Afonso Sá de Pinho Neto

Análise do processo de gestão da informação nos projetos artístico-culturais desenvolvidos pelo Centro Cultural Piollin

ao longo desta pesquisa, na medida em que é capaz de identificar e potencializar os recursos de informação que o Centro necessita, considerando a melhor forma de direcionar e gerenciar as informações na busca da consecução dos objetivos firmados pelas oficinas que são oferecidas pela instituição (Centro Cultural Piollin).

\section{REFERÊNCIAS}

BARBOSA, R. R. Gestão da informação e do conhecimento: origens, polêmicas e perspectivas. Informação \& Informação, Londrina, v. 13, n. esp., p. 1-25, 2008.

BARDIN, L. Análise de conteúdo. Lisboa: Edições 70, 1979.

BARRETO, A. A Questão da Informação. São Paulo em Perspectiva, v. 8, n. 4, p. 1-7, 1994, Fundação Seade, São Paulo.

CHOO, C. W. A. Organização do Conhecimento: como as organizações usam a informação para criar significado, construir conhecimento e tomar decisões. São Paulo: SENAC, 2003.

DAL GALLO, F. A renovação do circo e o circo social. In: Repertório: Teatro \& Dança, Salvador, p. 25-29, fev. 2010. Semestral. Disponível em: <http://www. portalseer.ufba.br/index.php/revteatro/issue/view/558>. Acesso em: 25 fev. 2016.

DAVENPORT, T. H. Ecologia da informação: por que só a tecnologia não basta para o sucesso na era da informação. São Paulo: Futura, 1998.

GIL, A. C. Como preparar projetos de pesquisa. 4. ed. São Paulo: Atlas, 2002.

KOBASHI, N. Y.; TÁLAMO, M. G. M. Informação: fenômeno e objeto de estudo da sociedade contemporânea. Transinformação. Campinas, n. 15, p. 7-21, 2003.

MCGEE, J. V.; PRUSAK, L. Gerenciamento estratégico da informação: aumente a competitividade e a eficiência de sua empresa utilizando a informação como uma ferramenta estratégica. Rio de janeiro: Campus, 1994.

MIRANDA, S. V. A gestão da informação e modelagem de processos. Revista do Serviço Público Brasília, 61 (1): 97-112 Jan/Mar 2010. 
SAYÃO, L. F. Modelos teóricos em Ciência da Informação: abstração e método científico. Ciência da Informação, Brasília, v. 30, n. 1, p. 82-91, 2001.

\title{
Title
}

Analysis of the information management process in the artistic and cultural projects developed by the Cultural Center Piollin

\begin{abstract}
Introduction: Information Science is the theoretical field that studies the mediating action between information and knowledge, dealing the information as an object that has the potential to generate knowledge on the individual and its reality. In this sense, the information can extend to the set of elements that make up a management process in order to order, coordinate and distribute information in a correct, political and social way, and this fact considers the context of the Third Sector Organizations.

Objective: This study aimed to analyze the actions that constitute the process of information management adopted in the implementation of artistic workshops developed by the Non-Governmental Organization Cultural Center Piollin.

Methodology: This research was oriented under a qualiquantitativa approach, characterized as an exploratory research, applied and descriptive, besides the use of literature, documentary and field researches for data collection. As data collection instruments semi-structured interviews were used for all public categories, analyzed by the Bardin content analysis (1979).

Results: The results reveal that the absence of a management that considers the information as a strategic and transformer element causes shortages and gaps that can influence the desired result by the workshops, contributing to reduce the benefits they could bring to the students, being the biggest one the use of artistic expressions as a way to educate for citizenship.

Conclusion: It is extremely necessary to Piollin make efforts to increase the information management to a strategic level, being able to block the shortcomings and gaps in terms of information, helping to achieve the objectives as desired by the workshops and the Centre.
\end{abstract}

Keywords: Information Science. Information management. Non-Governmental Organizations.

\section{Titulo}

Análisis del proceso de gestión de la información en los proyectos artísticos y culturales desarrollados por el Centro Cultural Piollin

\section{Resumen}

Introducción: Ciencias de la Información es el campo teórico que estudia la acción mediadora entre la información y el conocimiento, utilizando la información como un objeto que tiene el potencial de generar conocimiento sobre el individuo y su realidad. En este sentido, la información puede ampliar el conjunto de elementos que componen 
un proceso de gestión con el fin de ordenar, coordinar y distribuir la información de una manera correcta, política y social, una realidad que se extiende también al contexto de las organizaciones del Tercer Sector.

Objetivo: Este estudio tuvo como objetivo analizar las acciones que componen el proceso de gestión de la información adoptada en la realización de talleres artísticos desarrollados por la Organización No Gubernamental Centro Cultural Piollin.

Metodología: La investigación se orientó bajo un enfoque cuantitativo cualitativo, caracterizado por ser una investigación exploratoria, descriptiva y aplicada, y se utilizó de la búsqueda bibliográfica, documental y de campo para la recolección de datos. Como instrumentos de recolección de datos se utilizaron entrevistas semiestructuradas para todas las categorías de lo público, analizados por el análisis de contenido de Bardin (1979).

Resultados: Los resultados muestran que la ausencia de una gestión que incluye la información como elemento estratégico y transformador provoca la escasez y las deficiencias que pueden influir en el resultado deseado por los talleres, ayudando a reducir los beneficios que podría traer a los alumnos, incluyendo el objetivo final, que es utilizar la expresión artística como una forma de educar para la ciudadanía.

Conclusión: Es sumamente necesario que el Centro Piollin haga esfuerzos para aumentar la gestión de la información a un nivel estratégico, capaz de hacer frente a las deficiencias y carencias en términos de información, ayudando a conseguir los objetivos deseados por los talleres y el Centro.

Palabras clave: Ciencias de la Información. Gestión de la Información. Organizaciones no gubernamentales.

Recebido em: 10.04.2016

Aceito em: 18.11.2016 